\title{
Unmasking the reality of Covid-19 vaccine paranoia
}

Mohd Riyaz Beg ${ }^{1}$ and Ashi Siddiqui ${ }^{2}$

${ }^{1}$ Institute of Chemical Technology

${ }^{2}$ National Institute of Pharmaceutical Education and Research, SAS Nagar (Mohali)

December 22, 2020

\section{Hosted file}

Essay on covid vaccine_Preprint.pdf available at https://authorea.com/users/384436/articles/ 500046-unmasking-the-reality-of-covid-19-vaccine-paranoia 